\title{
Concrete cracking in tension members and application to deck slabs of bridges
}

\author{
A. Muttoni*and M. Fernández Ruiz ${ }^{\dagger}$
}

\begin{abstract}
Currently, estimations of the crack width in the deck slab of bridges given by codes of practice are based on either theoretical or empirical approaches considering mainly the monotonic loading behaviour. However, cracking in reinforced tensile members is highly influenced by the loading history (including both the loading and unloading processes). The irreversible non-linear behaviour of bond and the tensile response of concrete induce residual cracks of non negligible width.

This paper investigates the influence of this phenomenon and presents a physical model describing it. An analytical model is developed and its results are compared to various tests with good agreement. Finally, a simple design formula is derived and recommendations for its application to practical cases are proposed.
\end{abstract}

CE Database subject headings: Bridge decks; Tensile members; Cracking; Bond stress; Time dependence

\footnotetext{
*Professor, Ecole Polytechnique Fédérale de Lausanne, IS-BETON, bât. GC, Station 18, CH-1015, Lausanne, Switzerland. E-mail: aurelio.muttoni@epfl.ch

${ }_{\dagger}^{\dagger}$ Post-doctoral fellow, Ecole Polytechnique Fédérale de Lausanne, IS-BETON, bât. GC, Station 18, CH-1015, Lausanne, Switzerland. E-mail: miguel.fernandezruiz@epfl.ch
} 


\section{Introduction}

Crack control in the decks of continuous bridges over intermediate supports is often the governing design criterion for the choice of the amount of longitudinal prestressing of concrete bridges (in case of partial prestressing) as well as for the construction sequence and for the amount of passive longitudinal reinforcement of composite bridges.

Deck slabs over intermediate supports, as can be seen in figure 1, behave almost as pure tension ties in the longitudinal direction, assuming that the strain is constant over the depth of the slab and that the effect of local moments due to traffic loads can be neglected. Most models (Gergely and Lutz 1968, CEB-FIP 1990, Frosch 1999, CEN 2004) estimate the crack width in these elements under permanent load based on their monotonic loading response. However, under service conditions, the actual behaviour of a bridge is far from the assumption of monotonic loading because the structure is subjected during its life to additional external actions (traffic loads, temperature, load tests, ...) which cause continual unloading and reloading processes. Because of the irreversible unloading response of bond and concrete, these cycles increase the crack width in a tension member compared to the crack width under monotonic loading (Laurencet 1999, Gómez Navarro and Lebet 2001).

Within this context, this paper presents a new approach to the phenomenon of cracking, introducing a model that considers the effect of unloading on the crack width and that can be applied to perform a coherent check of the crack width of bridge deck slabs under permanent loads.

\section{Theoretical model}

\subsection{Reinforced tie behaviour}

The loading and unloading response of a reinforced tie is shown in figure 2. Under monotonic loading, it presents first an uncracked stage $(A B)$ until concrete reaches its effective tensile strength. At that point, the member enters in the crack development stage $(B C E)$ where several cracks are created (approximated by an horizontal line). Once the number of cracks is stabilised, a new phase controls the response of the tie in which the number of cracks remains constant but their openings increase with load $(E F I)$. This phase ends with the yielding of the reinforcement $(I)$. 
Three different stages may be considered for the unloading behaviour. Stage a $(C D)$ corresponds to unloading situations in the crack development stage. Stage $\mathbf{b}$ occurs at the beginning of unloading processes in the stabilised cracking phase $(F G)$. For large stress ranges, it may eventually enter into a third unloading stage named $\mathbf{c}(G H)$. All of these stages present a so-called negative tension-stiffening effect with larger strains for a given stress than those of the monotonic loading.

The complete unloading of a tie (points $D$ and $H$ of figure 2) leads to a residual strain and crack width. This shows that calculating the response of a tension member using a monotonic loading pattern may underestimate the actual value of the crack width (figure 3).

\subsection{Material and interface models}

Under service conditions, reinforcing steel remains in the elastic domain. However, both concrete and bond exhibit a non-linear response which needs to be considered to understand the loading and unloading behaviour of a cracked tensile member.

\subsubsection{Concrete}

A first crack is developed in concrete when its effective tensile strength $\left(f_{c t, e f f}\right)$ is reached. The effective tensile strength corrects the value of the tensile strength of concrete to account for the influence of the thickness of the element and its residual stresses.

After cracking, concrete still has the capacity to carry tensile stresses with a softening behaviour (Hillerborg et al 1976), depending on the crack width (the greater the opening, the smaller the tensile stress) as shown in curves $A B$ and $D E$ of figure 4 (a). The maximum crack width at which tensile stresses can be transmitted $\left(w_{c}\right)$ depends mainly on the concrete tensile strength and aggregate size, ranging usually between 0.15 and $0.25 \mathrm{~mm}$.

When cracked concrete is unloaded (curve $B C$ of figure 4 (a)), the complex geometry of the crack lips (that are no longer perfectly imbricated) leads to a residual opening. The stress required to reclose the crack can be estimated as a function of the crack width from the empirical expressions provided by Hordijk $(1991,1992)$. For cases where the maximum crack width before unloading is larger than $w_{c}$ it 
results:

$$
\bar{\sigma}_{c}=f_{c t, e f f}\left(0.004\left(\log \left[\frac{w}{w_{c}}\right]\right)^{5}-0.16 \sqrt{1-\frac{w}{w_{c}}}\right)
$$

\subsubsection{Bond}

According to Marti et al. (1996) and Alvarez (1998), a rigid-plastic bond law (part $A B C$ in figure 4 (b)) provides good results in reproducing the loading response of a tie. Kenel (2001) applied a similar law to unloading processes $(C D E$ of figure $4(\mathrm{~b}))$.

The value of $\tau_{a}$ can be estimated as (Alvarez 1998):

$$
\tau_{a} \approx 0.6 f_{c}^{\frac{2}{3}} \approx 2 f_{c t} \quad\left(f_{c}, f_{c t} \text { and } \tau_{a} \text { in }[\mathrm{MPa}]\right)
$$

For unloading, the value proposed by Laurencet (1999) can be adopted:

$$
\tau_{i} \approx \frac{\tau_{a}}{4}
$$

Under cyclic loading, the values of $\tau_{a}$ and $\tau_{i}$ decrease. According to the experimental results of Giuriani (1981) and Plaines et al. (1982) the reduction of $\tau_{i}$ quickly stabilises around $\tau_{i, \infty} \approx 0.50 \tau_{i}=\tau_{a} / 8$. The reduction of $\tau_{a}$ is smaller and may be approximated as $\tau_{a, \infty} \approx 0.70 \tau_{a}$ (Tassios 1979; Balázs 1991).

\subsection{Monotonic loading of a cracked reinforced tie}

After concrete cracking, the response of a reinforced member may be characterised using the following considerations:

1. The cross-sectional equilibrium of forces yields $\sigma A=\sigma_{s} A_{s}+\sigma_{c} A_{c}$ (where $\sigma$ is the average stress in the tie and $A$ is its area). If the tensile softening stress of the concrete in the crack is neglected, then $\sigma=\sigma_{s a} \rho$ (where $\rho=A_{s} / A$ is the reinforcement ratio and $\sigma_{s a}$ the steel stress in the crack, see figure 5)

2. The steel stress distribution along the axis of the bar is obtained by performing the equilibrium of forces of the bar with the rigid-plastic bond law over the transfer length $\left(l_{b a}\right)$ :

$$
\sigma_{s a} \frac{\pi}{4} \phi_{s}^{2}=\pi \phi_{s} l_{b a} \tau_{a} \rightarrow l_{b a}=\frac{\sigma_{s a} \phi_{s}}{4 \tau_{a}}
$$


The maximum value of $l_{b a}$ can be estimated considering that $\sigma_{s a}=f_{c t, e f f} / \rho$ at the end of the crack development phase, thus:

$$
l_{b a, \max }=\frac{\phi_{s} f_{c t, e f f}}{4 \rho \tau_{a}}
$$

3. Concrete strains are neglected in comparison to steel strains. Then, the crack width may be obtained as $w=\int_{s_{c}}\left(\varepsilon_{s}-\varepsilon_{c}\right) d x \approx \int_{s_{c}} \varepsilon_{s} d x$ ( $s_{c}$ being the distance between cracks)

Based on these considerations, the response of a member under monotonic load can be obtained analytically in a closed form. For the crack development stage (figure 5 (a)), the crack width after the loading process $\left(w_{l}\right)$ can be calculated as:

$$
w_{l}=\frac{\sigma_{s a}^{2} \phi_{s}}{4 E_{s} \tau_{a}}=\frac{\sigma^{2} \phi_{s}}{4 \rho^{2} E_{s} \tau_{a}}
$$

For the stabilised cracking phase (figure 5 (b)) the maximum crack width in the element can be estimated on the basis of the maximum value of $l_{b a}$ (eq. (5)), similar to the values proposed by (CEB-FIP 1990, CEN 2004). The resulting crack width is then:

$$
w_{l}=\left(\frac{2 \sigma_{s a}}{E_{s}}-\frac{f_{c t, e f f}}{\rho E_{s}}\right) \frac{\phi_{s} f_{c t, e f f}}{4 \rho \tau_{a}}=\left(2 \sigma-f_{c t, e f f}\right) \frac{\phi_{s} f_{c t, e f f}}{4 \rho^{2} E_{s} \tau_{a}}
$$

\subsection{Unloading of a cracked reinforced tie}

When a cracked tie is unloaded, concrete may develop compressive stresses (see figure 4 (a)) whose values may be important and cannot be neglected in the cross-sectional equilibrium of the element, then:

$$
\sigma_{p e r}=\sigma_{s i} \rho+\bar{\sigma}_{c}
$$

with the stress range of the tie: $\Delta \sigma=\Delta \sigma_{s} \rho-\bar{\sigma}_{c}$ (see figure 6).

For the rigid-plastic bond law (figure 4 (b)) and neglecting again concrete strains compared to steel strains, the crack width $w_{\text {per }}$ (see figure 3) can be calculated for the different unloading regimes (see figure 6):

- Stage a: Unloading in the crack development stage:

$$
w_{p e r}=\left[\left(\sigma_{p e r}+\Delta \sigma\right)^{2}-\left(\Delta \sigma+\bar{\sigma}_{c}\right)^{2} \frac{\tau_{a}}{\tau_{a}+\tau_{i}}\right] \frac{\phi_{s}}{4 \rho^{2} E_{s} \tau_{a}}
$$


- Stage b: Unloading in the stabilised cracking stage when the unloaded length $l_{b i}$ (figure $\left.6(\mathrm{~b})\right)$ is smaller than $l_{b a}$ :

$$
w_{p e r}=\left[2\left(\sigma_{p e r}+\Delta \sigma\right)-f_{c t, e f f}-\frac{\left(\Delta \sigma+\bar{\sigma}_{c}\right)^{2}}{f_{c t, e f f}} \frac{\tau_{a}}{\tau_{a}+\tau_{i}}\right] \frac{\phi_{s} f_{c t, e f f}}{4 \rho^{2} E_{s} \tau_{a}}
$$

- Stage c: Unloading in the stabilised cracking stage when $l_{b i} \equiv l_{b a}$ :

$$
w_{p e r}=\left[2\left(\sigma_{p e r}-\bar{\sigma}_{c}\right)+\frac{\tau_{i} f_{c t, e f f}}{\tau_{a}}\right] \frac{\phi_{s} f_{c t, e f f}}{4 \rho^{2} E_{s} \tau_{a}}
$$

Note that the last equation does not depend on the stress range of the tie $(\Delta \sigma)$.

\section{Comparison with test results}

Farra and Jaccoud (1993) performed a series of tests on reinforced ties studying both their loading behaviour and their residual crack width after unloading. Figure 7 compares their results to the analytical model which gives good agreement for the residual crack width.

The model is further compared in figure 8 to the tests performed by Laurencet et al. (1997) on several reinforced and prestressed (unbounded) ties with low reinforcement ratios. A good agreement is again achieved in both the loading and unloading branches.

\section{Proposal of design formula and comparison with other models}

\subsection{Design formula}

Equations (9) to (11) may be used to obtain the maximum allowable stress in a tension member for a permanent load combination with a given crack width limit. The value of the crack width limit is usually defined in codes of practice depending on the exposure conditions and the presence or not of prestressing. It can be observed (figure 9) that an important part of the response of the tie is independent of the stress range $(\Delta \sigma)$ corresponding to unloading situations under stage $\mathbf{c}$ (equation (11)).

For practical purposes, the value of the lower plateau can be used. This is the correct value for bridge decks with usual reinforcement ratios and bar diameters where $\Delta \sigma$ is greater than 2 or 3 MPa. This value is otherwise conservative. A more precise value in stages $\mathbf{a}$ and $\mathbf{b}$ can be obtained using equation (9) for stage a and (10) for stage $\mathbf{b}$. 
However, equation (11) has been derived without considering time-dependent concrete strains, whose effect should be included in the analysis of cracked members because the crack width increases with time as rheological strains develop (Jaccoud and Charif 1987). Tensile creep strains of concrete can usually be neglected in comparison to shrinkage strains and the increase in the crack width can be estimated as:

$$
\Delta w \cong-\varepsilon_{c s} s_{c} \rightarrow w_{p e r, \infty}=w_{p e r}-\varepsilon_{c s} s_{c}
$$

where $s_{c}$ is the maximum distance between cracks (equal to $2 l_{b a}$ for the stabilised cracking phase) and $\varepsilon_{c s}$ represents the shrinkage strain. This increase in crack width has to be introduced in equation (11) using $w_{p e r}=w_{p e r, \infty}+\varepsilon_{c s} s_{c}$ (where $w_{p e r, \infty}$ is the long-term crack width) and considering bond stresses under cyclic loading $\left(\tau_{i, \infty}\right.$ and $\left.\tau_{a, \infty}\right)$. The following expression is obtained for the maximum allowable stress in the tie $\left(\sigma_{\text {all }}\right)$ :

$$
\sigma_{\text {all }}=\rho E_{s} \varepsilon_{c s}+w_{p e r, \infty} \frac{2 \rho^{2} \tau_{a} E_{s}}{\phi_{s} f_{c t, e f f}}-\frac{\tau_{i, \infty} f_{c t, e f f}}{2 \tau_{a}}+\bar{\sigma}_{c}
$$

Introducing the values of $\tau_{a}=2 f_{c t}$ and $\tau_{i, \infty}=f_{c t} / 4$ and expressing the bridge deck effective tensile strength as a function of the concrete tensile strength (using $f_{c t, e f f}=k f_{c t}$ ), it results:

$$
\sigma_{\text {all }}=\rho E_{s} \varepsilon_{c s}+w_{p e r, \infty} \frac{4 \rho^{2} E_{s}}{k \phi_{s}}-\frac{k f_{c t}}{16}+\bar{\sigma}_{c}
$$

The value of $\bar{\sigma}_{c}$ can be obtained from equation (1). Considering $w_{c}=0.2 \mathrm{~mm}$, its value for $w_{r e s, \infty}=0.1$ $\mathrm{mm}$ would be $\bar{\sigma}_{c}=-0.1 f_{c t, e f f}$ and for $w_{r e s, \infty}=0.2 \mathrm{~mm}$ would be $\bar{\sigma}_{c}=0 \mathrm{MPa}$. For usual deck thicknesses, $k$ may be adopted as $k=0.90(e=250 \mathrm{~mm})$ and $k=0.85(e=350 \mathrm{~mm})$.

This formula may also be expressed isolating $\rho$ as:

$$
\rho=\frac{-E_{s} \varepsilon_{c s}+\sqrt{E_{s}^{2} \varepsilon_{c s}^{2}-4\left(\bar{\sigma}_{c}-\frac{k f_{c t}}{16}-\sigma_{\text {all }}\right)\left(\frac{4 w_{p e r, \infty} E_{s}}{k \phi_{s}}\right)}}{\frac{8 w_{p e r, \infty} E_{s}}{k \phi_{s}}}
$$

The first design formula (eq. (14)) is aimed at helping in the predimensioning of structures, obtaining the necessary prestressing of partially prestressed concrete bridges (once the admissible stress in the deck has been estimated for a given crack width, reinforcement ratio and bar diameter) or the construction sequence of composite bridges. As shown in figure 10, the bar diameter $\left(\phi_{s}\right)$ has an important influence on the response of the element.

The second formula (eq. (15)) may, on the other hand, be used in the final dimensioning of the structure to determine the necessary reinforcement of the deck slab if the crack control criterion is governing. 


\subsection{Estimation of crack width by other models and comparison with design formula}

The results obtained with the proposed design formula (14) are compared in this section to various existing models.

The first model that is compared to the design formula is the one proposed by the MC-90 (CEB-FIP 1990), which estimates the allowable stress in a tie for repeated or long-term loading in the stabilised cracking stage as:

$$
\sigma_{\text {all }}=\rho E_{s} \varepsilon_{c s}+w_{k} \frac{3.6 \rho^{2} E_{s}}{\phi_{s}}+0.38 k f_{c t}
$$

Comparing this formula to eq. (14), it can be seen that shrinkage strains have the same effect on both expressions and that also similar contributions related to the admissible crack width are expected. The main difference between both formulations is found in the tension-stiffening term, positive according to MC-90 $\left(0.38 k f_{c t}\right)$ and negative according to the proposed model $\left(-k f_{c t} / 16+\bar{\sigma}_{c}\right)$. EC-2 (CEN 2004) proposes an expression similar to that of MC-90 but without considering the effect of shrinkage strains. Also, equation (14) is compared to two models which have been the basis of the crack control formulae for American codes (as cited in DeStefano et al. (2003)). The first one was proposed by Gergely and Lutz (1968) estimating the crack width by means of a dimension-dependent empirical formula. The second model is due to Frosch (1999), which proposes a theoretically-derived expression. None of these models consider the effect of shrinkage strains.

Figure 11 compares the results of the previous models to equation (14) on a reference tie. Four cases are presented showing the influence of the crack width and shrinkage strains. When shrinkage strains are neglected, all models yield similar admissible stresses for the tie. The proposed formula, however, provides a slightly smaller allowable stress due to the consideration of the unloading behaviour. When shrinkage strains are included, only the formula proposed in this paper and MC-90 modify their response, reducing the allowable stress in the tie. 


\section{Conclusions}

This paper investigates concrete cracking in the deck slab of bridges due to longitudinal bending, considering their unloading response and proposing an analytical model to design elements according to this phenomenon. The main contributions and conclusions of this paper are the following:

1. Estimating the crack width in deck slabs of bridges under permanent load (service limit state verification) requires to consider their unloading behaviour.

2. A cracked tie, after an unloading process, presents a residual crack width due to the non-linear unloading response of bond and concrete, which can be interpreted as a negative tension-stiffening effect.

3. A simplified rigid-plastic bond law provides satisfactory agreement with test results and allows to derive analytical expressions describing the loading and unloading response of a tie.

4. Different unloading stages can be developed by a tension member. For deck slabs of bridges, however, only one is governing. Its response depends only on the permanent stress in the element and not on its stress range. For this case, simple design formulae may be derived to estimate the crack width in tension members.

5. The influence of shrinkage strains should not be neglected in the estimation of the long-term crack width of cracked members and it is included in the proposed model. The influence of tensile creep strains may, on the other hand, be neglected.

\section{Notation}

The following symbols are used in this paper:

$A \quad=\quad$ cross-sectional area

$A_{p r}=\quad$ prestressing cross-sectional area

$A_{s}=$ reinforcement cross-sectional area

$E_{s}=\quad$ steel elastic modulus

$f_{c}=\quad$ concrete uniaxial compressive strength 


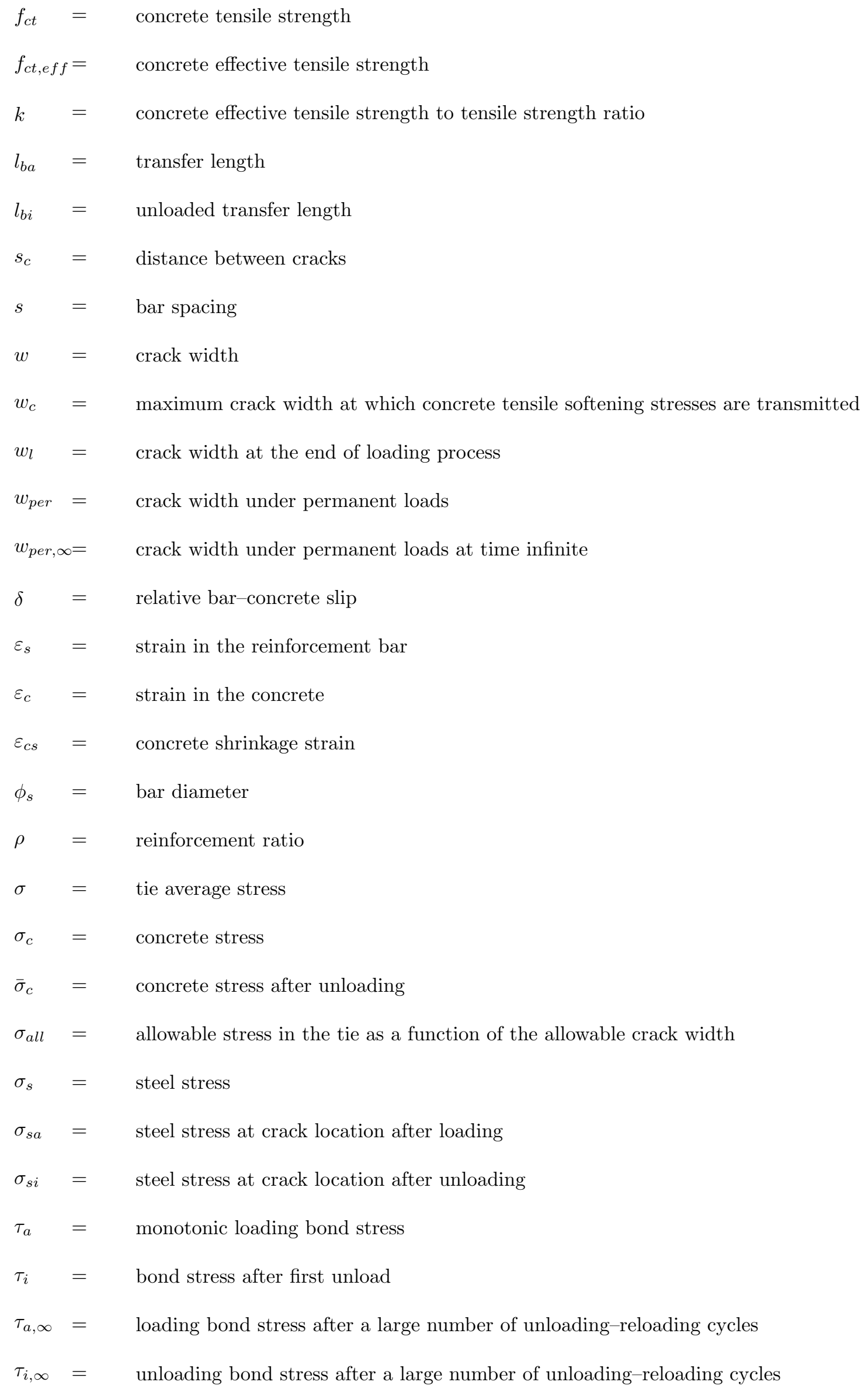




\section{References}

Alvarez, M. (1998). Influence of bond behaviour in the deformation capacity of reinforced concrete (in German, Einfluss des Verbundverhaltens auf das Verformungsvermögen von Stahlbeton), phD. Thesis, IBK, Eidgenössische Technische Hochschule Zürich, Zürich, Switzerland.

Balázs, G. L. (1991) "Fatigue of Bond", ACI Materials Journal, Vol. 88, No. 6, pp. 620-629

CEB-FIP (1990). Model code for concrete structures, Comité Euro-International du Béton, Lausanne, Switzerland.

CEN (2004). Eurocode 2: Design of concrete structures - Part 1-1: General rules and rules for buildings, Comité Européen de Normalisation, Brussels, Belgium.

DeStefano, R., J., Evans, J., Tadros, M., K. and Sun, C. (2003). "Flexural crack control in concrete bridge structures", $3^{\text {rd }}$ International Symposium on High Performance Concrete (ISHPC), Orlando, USA.

Farra, B. and Jaccoud, J-P. (1993). Influence of concrete and reinforcement on cracking of concrete structures. Test report of short-term imposed strains on ties (in French, Influence du béton et de l'armature sur la fissuration des structures en béton. Rapport des essays de tirants sous déformation imposée de courte durée), IBAP, Pub. 140, École Polytechnique Fédérale de Lausanne, Lausanne, Switzerland.

Frosch, R. J. (1999). "Another look at cracking and crack control in reinforced concrete", ACI Structural Journal, May-June, pp. 437-442.

Gergely, P. and Lutz, L. A. (1968). "Maximum crack width in reinforced concrete flexural members", Causes, Mechanism and Control of Cracking in Concrete, SP-20, American Concrete Institute, Farmington Hills, Mich., pp. 87-117.

Giuriani, E. (1981). "Experimental investigation on the bond-slip law of deformed bars in concrete", IABSE Colloquium Delft 1981, Advanced Mechanics of Reinforced Concrete, Reports of the working commissions, Vol. 34, International Association for Bridge and Structural Engineering, Switzerland, pp. $121-142$. 
Gómez Navarro, M. and Lebet, J.-P. (2001). "Concrete cracking in composite bridges: Tests, models and design proposals", Structural Engineering International, International Association for Bridge and Structural Engineering, Vol. 11, No. 3, Switzerland, pp. 184-190.

Hillerborg, A., Modéer, M. and Petersson, P. E., (1976). "Analysis of crack formation and crack growth in concrete by means of fracture mechanics and finite elements", Cement and Concrete Research, Vol. 6, pp. $773-782$.

Hordijk, D. A. (1991). Local approach to fatigue of concrete, phD. Thesis, Technische Universiteit Delft (Ed. W. D. Meinema), Delft, the Netherlands.

Hordijk, D. A. (1992). Tensile and tensile fatigue behaviour of concrete; experiments, modelling and analysis, Heron, Lab. Sterin, Technische Universiteit Delft, 37/1, Delft, the Netherlands.

Jaccoud, J-P and Charif, H. (1987). Minimal reinforcement for crack control on concrete structures. Final test report, series $C$ (in French, Armature minimale pour le contrôle de la fissuration des structures en béton, Rapport final des essays série C), IBAP, Pub. 114, École Polytechnique Fédérale de Lausanne, Lausanne, Switzerland.

Kenel, A. (2001). Flexural behaviour and minimal reinforcement in reinforced concrete structural members (in German, Biegetragverhalten und Mindestbewehrung von Stahlbetonbauteilen), phD. Thesis, IBK, Eidgenössische Technische Hochschule Zürich, Zürich, Switzerland.

Laurencet, P., Jaccoud, J-P and Favre, R. (1997). Cracking in prestressed concrete structures under cyclic loading - Test report (in French, Fissuration des structures en béton précontraint sous l'effet d'actions cycliques - Rapport des Essais), IBAP, Pub. 145, École Polytechnique Fédérale de Lausanne, Lausanne, Switzerland.

Laurencet, P. (1999). Prestressing and minimal reinforcement for the control of the residual crack width (in French, Précontrainte et armature pour contrôler l'ouverture résiduelle des fissures), phD. Thesis, IBAP, École Polytechnique Fédérale de Lausanne, Lausanne, Switzerland.

Marti, P., Alvarez, M., Kaufmann, W. and Sigrist, V. (1998). "Tension chord model for structural concrete", Structural Engineering International, IABSE, Vol 8, No 4, pp. 287-298. 
Plaines, P., Tassios, T. and Vintzeleou, E. (1982). "Bond relaxation and bond-slip creep under monotonic and cyclic actions", Proceedings of the International Conference at Paisley, Paisley 14-16 June 1982, pp. $193-205$.

Tassios, T. P. (1979). "Properties of Bond Between Concrete and Steel Under Load Cycles Idealising Seismic Actions", CEB Bulletin d'Information, No. 131, Vol 1, pp.67-121. 


\section{Figure captions}

Figure 1: Deck slab over intermediate support: (a) longitudinal scheme of a bridge; (b) cracking pattern for prestressed and composite bridges and (c) deck slab as a tension member

Figure 2: $\quad$ Stress-strain response of a reinforced concrete tie and different unloading stages

Figure 3: $\quad$ Stress-strain and stress-crack width relationship in a reinforced concrete tie

Figure 4: Material and interface laws: (a) concrete tensile response and (b) rigid-plastic bond law

Figure 5: Loading of a reinforced tie: (a) sketch of the system; (b) steel stress distribution at crack development stage and (c) stabilised cracking stage

Figure 6: Steel stress distribution at unloading states of a tie: (a) stage a; (b) stage b and (c) stage c

Figure 7: Comparison of the analytical model $\left(k=0.95 ; \tau_{a}=2 f_{c t}\right.$ and $\left.\tau_{i}=0.5 f_{c t}\right)$ with the test results by Farra and Jaccoud (1993) for series N10 and N42: (a) $\phi_{s}=10 \mathrm{~mm}$; (b) $\phi_{s}=14 \mathrm{~mm}$ and (c) $\phi_{s}=20 \mathrm{~mm}$

Figure 8: Comparison of the analytical model $\left(k=0.95 ; \tau_{a}=2 f_{c t}\right.$ and $\left.\tau_{i}=0.5 f_{c t}\right)$ with the tests by Laurencet et al. (1997)

Figure 9: Plots of admissible stresses as a function of the stress range for various reinforcement ratios with and without shrinkage strains

Figure 10: Plots of admissible stresses (stage c) as a function of the reinforcement ratio for various bar diameters with and without shrinkage strains

Figure 11: Comparison of the proposed model with different models: (a) properties of the specimen analysed and (b) plots for various shrinkage strains and crack widths 
(a)

(b)
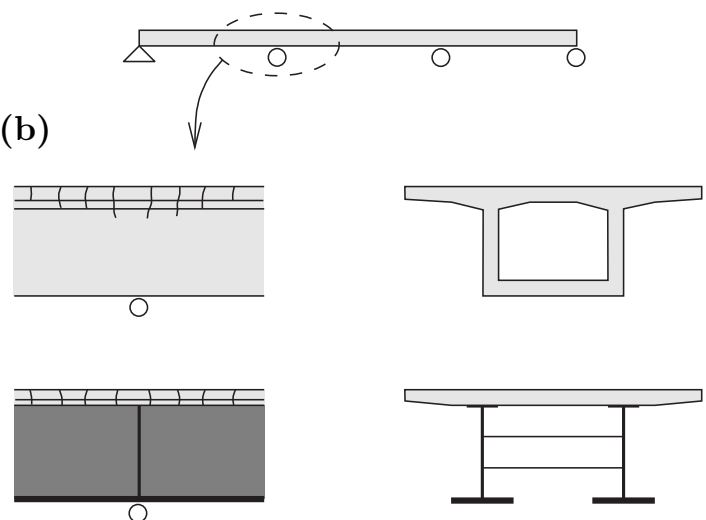

(c)

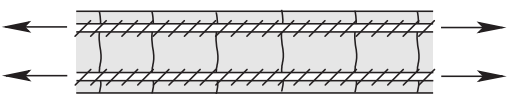

Figure 1

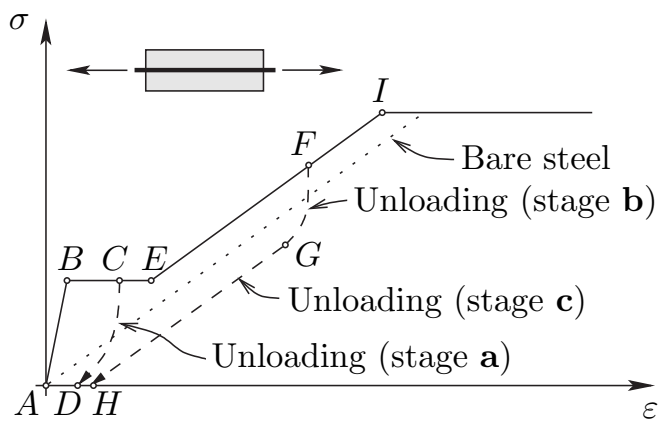

Figure 2

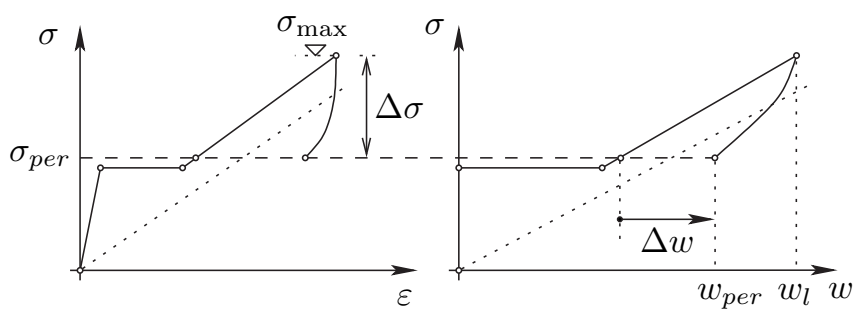

Figure 3 
(a)

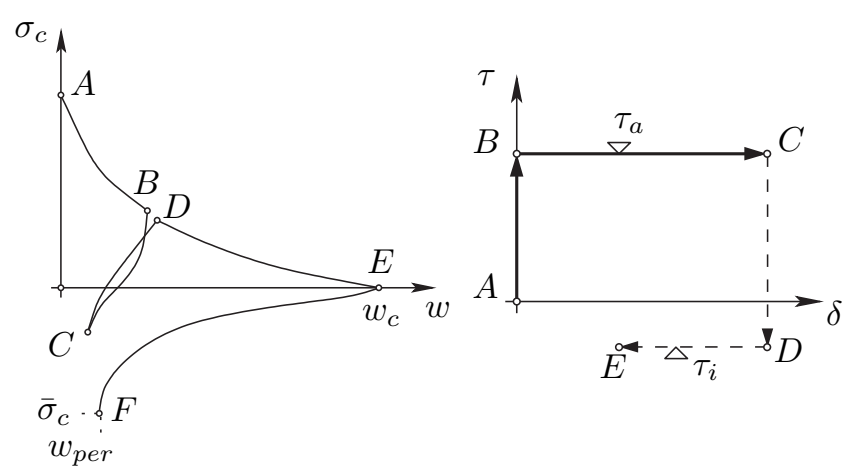

(b)

Figure 4

(a)

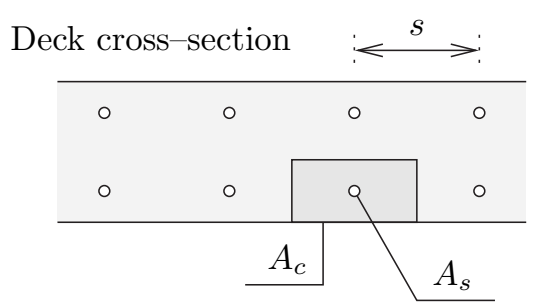

Tension member

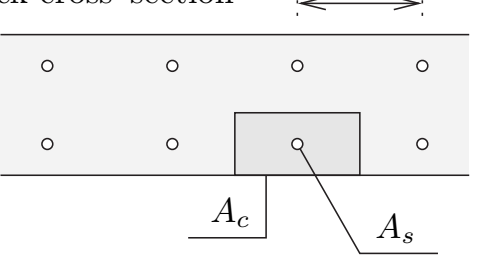

$\leftarrow$ ک

(b)

(c)
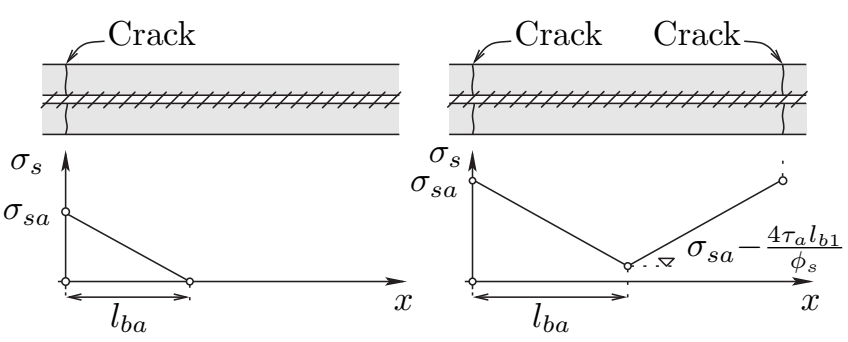

Figure 5 
(a)
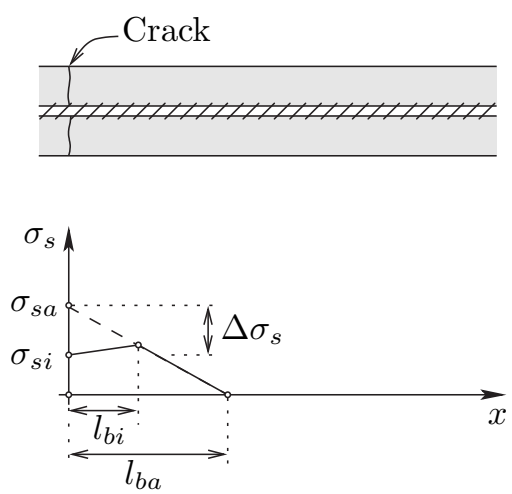

(b)
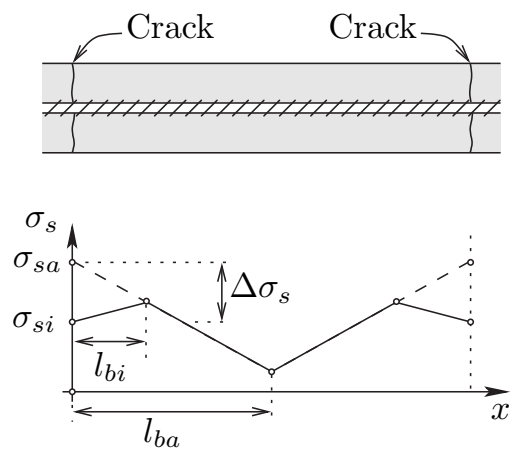

Figure 6 (c)

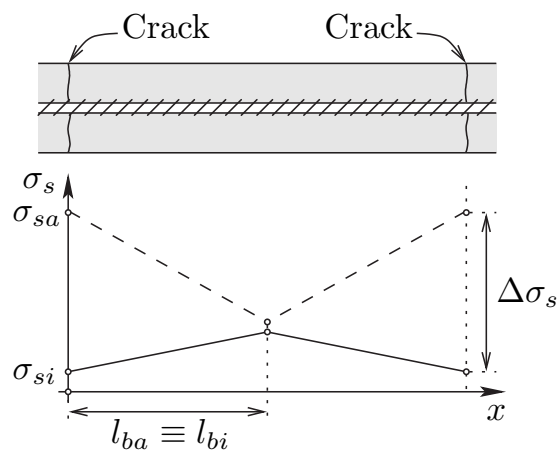


(a)

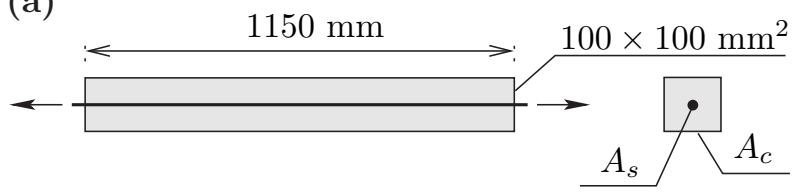

\begin{tabular}{|l|c|c|}
\cline { 2 - 3 } \multicolumn{1}{c|}{} & $f_{c t}[\mathrm{MPa}]$ & $\phi_{s}[\mathrm{~mm}]$ \\
\hline N10-10-1 & 2.5 & 10 \\
\hline N42-10-1 & 3.4 & 10 \\
\hline N10-14-1 & 2.5 & 14 \\
\hline N42-14-1 & 3.4 & 14 \\
\hline N10-20-2 & 2.5 & 20 \\
\hline N42-20-1 & 3.4 & 20 \\
\hline
\end{tabular}

(b)

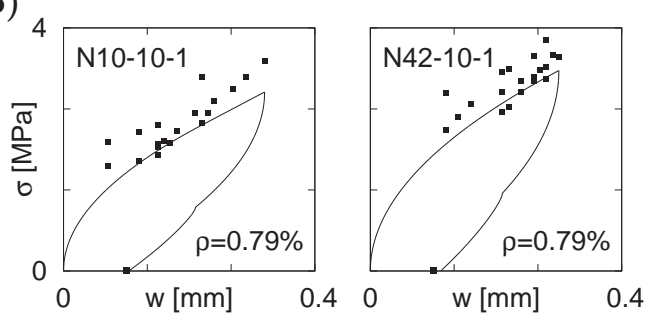

(c)
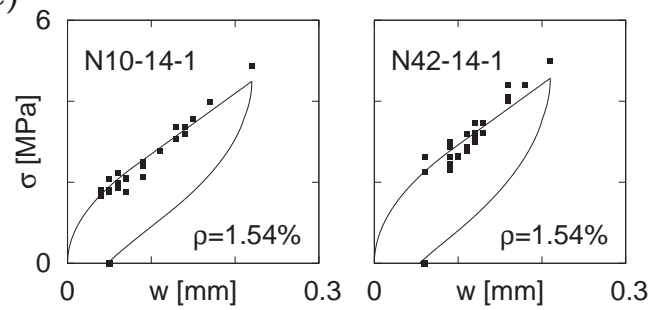

(d)

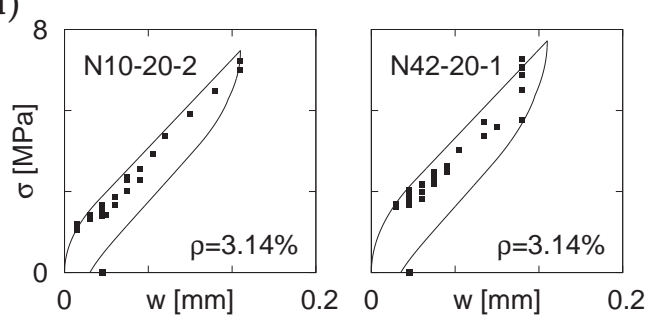

Figure 7 
(a)

Dimensions in [mm]

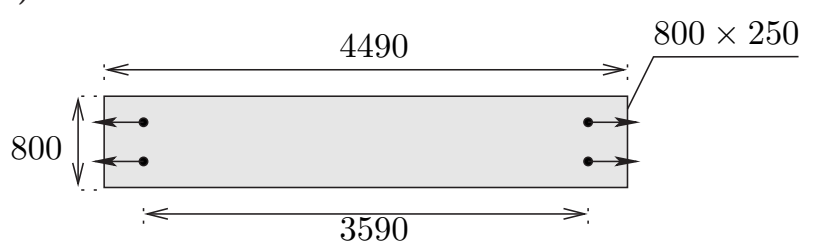

\begin{tabular}{|c|c|c|c|}
\hline & $\because \mathrm{S} 01$ & $\because \mathrm{S} 02$ & $\because \mathrm{P} 12$ \\
\hline$A_{s}$ & $8 \phi 14$ & $8 \phi 12$ & $8 \phi 12$ \\
\hline$A_{p r}\left[\mathrm{~mm}^{2}\right]$ & - & - & $1 \times 150$ \\
\hline$f_{c t}[\mathrm{MPa}]$ & 2.6 & 2.8 & 3.0 \\
\hline & $\begin{array}{ll} & 0 \\
& \text { P21 } \\
& \end{array}$ & \begin{tabular}{ll|} 
& $\circ 22$ \\
$\therefore$ & P22 \\
$\therefore$ &
\end{tabular} & $\because \quad$ P23 \\
\hline$A_{s}$ & $8 \phi 14$ & $8 \phi 12$ & $8 \phi 10$ \\
\hline$A_{p r}\left[\mathrm{~mm}^{2}\right]$ & $3 \times 150$ & $3 \times 150$ & $3 \times 150$ \\
\hline$f_{c t}[\mathrm{MPa}]$ & 2.4 & 2.4 & 2.8 \\
\hline
\end{tabular}

(b)

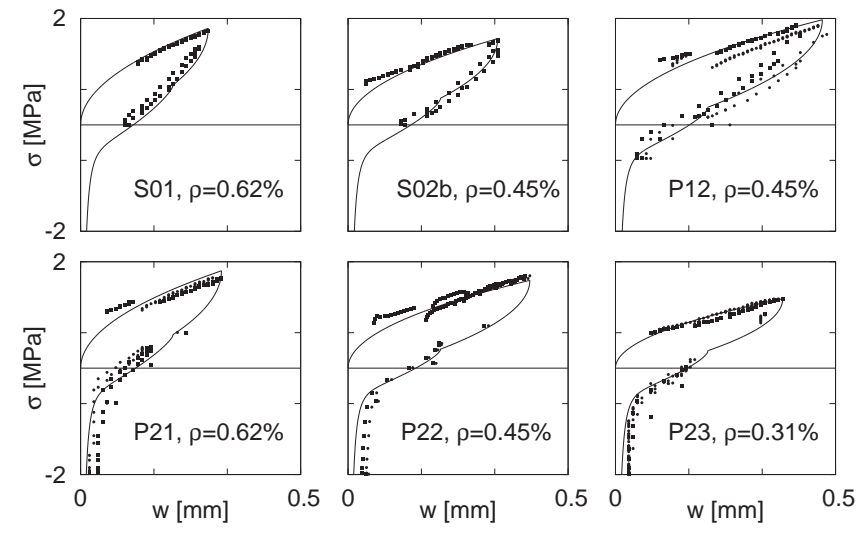

Figure 8 

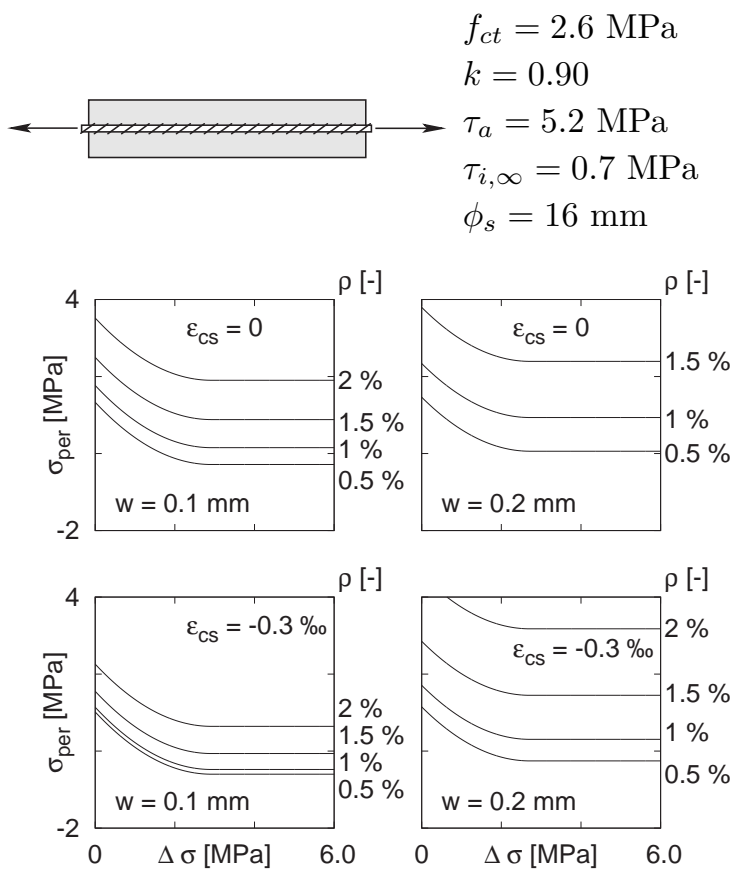

Figure 9
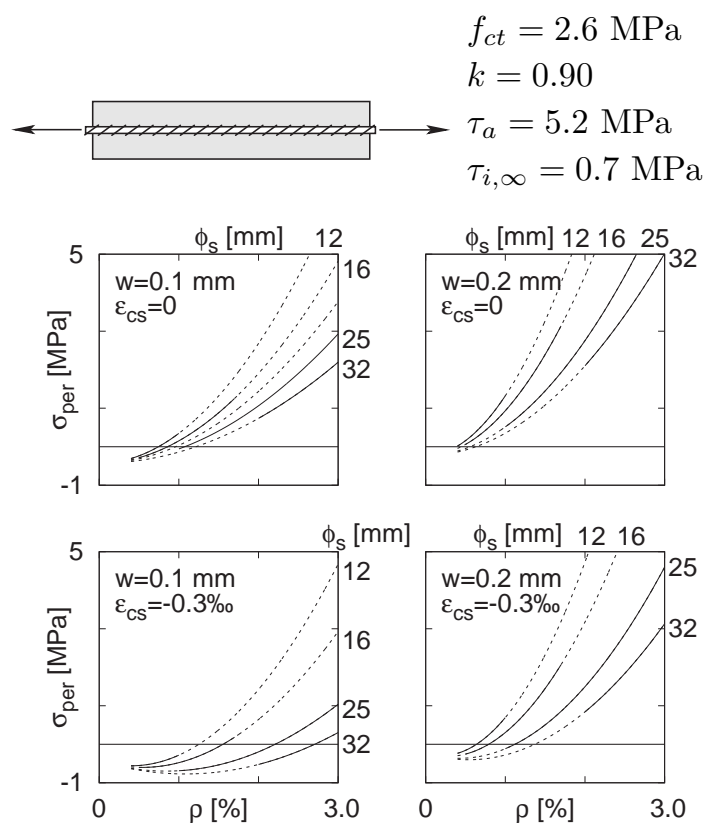

Figure 10 
(a)

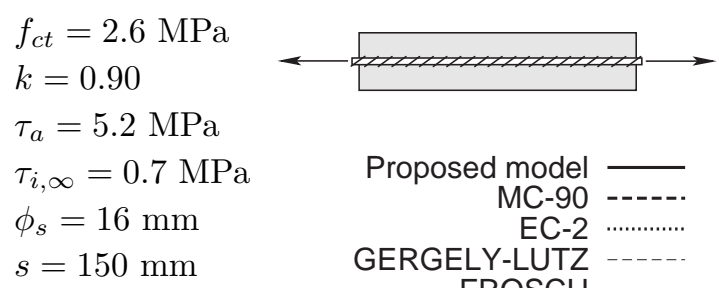

(b)
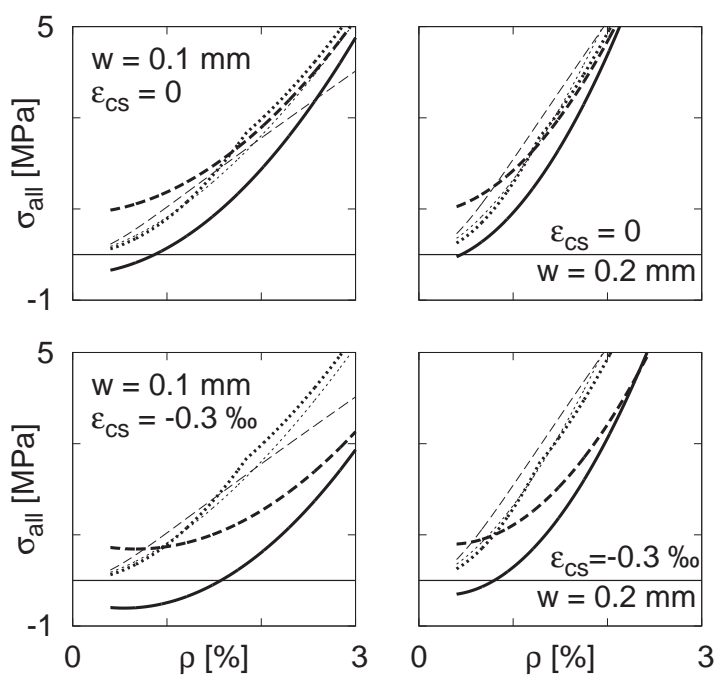

Figure 11 